\title{
THE ASSESSMENT OF INFLUENCE OF THERMAL AGING TO DIELECTRIC PROPERTIES OF XLPE INSULATION USING DIELECTRIC RELAXATION SPECTROSCOPY
}

\author{
ROMAN CIMBALA*, MARTIN GERMAN-SOBEK, SAMUEL BUCKO* \\ * Department of Electrical Power Engineering, Faculty of Electrical Engineering and Informatics, \\ Technical University of Košice, Letná 9, 04200 Košice, Slovak Republic, tel. +421 55602 3557, e-mail: roman.cimbala@tuke.sk
}

\begin{abstract}
The change of dielectric parameters points to the aging or defect of insulation. Cross-linked polyethylene (XLPE) is the globally preferred modern insulation for power cables, both for distribution and transmission system applications. Many studies and experiments show an influence of aging to degradation of XLPE insulation. It is subsequently reflected by changing of dielectric parameters of insulation. The measurement of dielectric parameters of XLPE cable sample was carried out by the method of dielectric relaxation spectroscopy (DRS) in frequency domain. DRS represents method suitable for measuring the dielectric parameters of polymeric composites during aging. The results are compared and it was observed a change of parameters in consequence of additional aging.
\end{abstract}

Keywords: degradation, dielectric relaxation spectroscopy, insulation, thermal aging, XLPE.

\section{INTRODUCTION}

The insulation system is an important and sensitive part of any electrical equipment. Nowadays, as insulation system of power cables are widely used polymeric materials. Cross-linked polyethylene (XLPE) is the main polymeric insulation for high-voltage distribution power cables. XLPE is characterized by excellent physical, chemical and electrical properties. During operation, the insulation system may be exposed to high currents and voltages and it is a critical part. Therefore, it is expected high resistance against possible failures. Damage of insulation can lead to equipment failure and other disorders. [1] - [5]. Ageing processes are the most acting on the parameters and quality of insulation and it is a phenomenon that essentially cannot be affected.

\section{DEGRADATION OF XLPE INSULATION}

Properties of XLPE cable insulation can be modified by used production technologies. The material properties are influenced by the manufacturing process, heating and cooling temperatures and time. The cooling process significantly influences the morphology and thus the electrical properties of XLPE insulation [7].

The breakdown of XLPE is closely related to electrical trees and partial discharges and it was found that the breakdown voltage decreased with an increasing frequency [9], [10].

Stability of microstructure and composition of the insulating material is changing due to degradation processes. These changes result in changing behaviour of insulation material from perspective of polarization processes. Aging in a polymer changes the electrical, physical, mechanical and morphological properties of the insulation [11]. All these properties are influencing the dielectric parameters and characteristics of insulation [12]. During thermal aging, several structural changes occur such as variation in crystalline, chain scission and variation in heat of fusion and in melting point [8], [13].
It is well known that the aged XLPE cable insulations have many microvoids whose number increases with the distance from the cable conductor. Their dimensions and number depend on the technology and kind of the cable insulation. It is generally assumed that during production, microvoids, impurities, water and residual products from crosslinking will be collected in amorphous regions of the insulation. Increasing of aging temperature, the microvoids are of larger size [14].

All cables with XLPE insulation contain antioxidants which protect the XLPE from oxidation during the extrusion and cross-linking process, and also during the service life of the cable. The rate at which the antioxidant is used depends on temperature. The normal maximum operating temperature of XLPE cables is $90^{\circ} \mathrm{C}$. Tests have shown that XLPE cables can operate at temperature of $105^{\circ} \mathrm{C}$ for a limited time without significantly reducing the service life of cables. Increasing the operating temperature will increase the rate at which the anti-oxidant is used up and hence reduce the service life of XLPE insulation. At temperatures in excess of $105{ }^{\circ} \mathrm{C}$ deformation of XLPE readily occurs, particularly at positions where the insulation is under mechanical stress. The maximum overload temperature of XLPE is limited to $105^{\circ} \mathrm{C}$ [6], [15], [16], [17], [18].

\section{MEASUREMENT METHODS}

Relaxation process of XLPE can reflect the insulation ageing information, thus calculating the values of the dissipation factor and capacitance can be used to assess the ageing condition of XLPE cable insulation. One of the methods for detection of insulating state of XLPE insulation is measurements of dielectric parameters using the dielectric relaxation spectroscopy (DRS). DRS is a one of the non-destructive measurement methods and uses polarization as the response of the sample on a timedependent electric field. For electrolyte solutions, polarization essentially originates from the oriented fluctuations of permanent dipoles (solvent molecules, ion 
pairs), from intramolecular polarizability and from ion motion. It can be investigated either in the time domain or as a function of the frequency of harmonic field. Principle of this method is based on examination of molecular dynamics of polarized and polar materials. DRS is widely applied in the characterization of ion-conducting solids and polymers [19], [20], [21], [22].

In the frequency domain, the polarization phenomena follow the alternating electric field. DRS is focused on the measurement of the frequency dependence of real and imaginary components of the impedance of the investigated samples. DRS evaluates the dielectric response function in the frequency domain using the dielectric dissipation loss factor $\tan \delta$ and complex capacitance $C(\omega)$. Using DRS in frequency domain can be evaluated the effect of temperature and thermal aging on dielectric parameters and change of properties of investigated insulation material after aging and degradation processes [21].

The total current flowing across the material when exposed to voltage $U(\omega)$ can be expressed as [21]:

$$
I(\omega)=i \omega C_{0}\left[\varepsilon_{\infty}+\chi^{\prime}(\omega)-i\left(\frac{\sigma_{0}}{\varepsilon_{0} \omega}+\chi^{\prime \prime}(\omega)\right)\right] U(\omega)
$$

Complex electrical induction $D(\omega)$ is proportional to the complex dielectric permittivity $\varepsilon(\omega)$ according to the relation [21]:

$$
\underline{D}(\omega)=\varepsilon_{0} \underline{\varepsilon}(\omega) \underline{E}(\omega)=\varepsilon_{0}\left[1+\chi^{\prime}(\omega)-\underline{i} \chi^{\prime \prime}(\omega)\right] \underline{E}(\omega)
$$

Where

$$
\underline{\varepsilon}(\omega)=\varepsilon^{\prime}(\omega)-\underline{i} \varepsilon^{\prime \prime}(\omega)=\left(1+\chi^{\prime}(\omega)\right)-\underline{i} \chi^{\prime \prime}(\omega)
$$

Actual measurements of this dielectric response in the frequency domain are difficult to perform, if the frequency range becomes very large. The measured relative dielectric permittivity is defined from the following relation [21]:

$$
\underline{j}(\omega)=i \omega \varepsilon_{0} \underline{\widetilde{\varepsilon}}_{r}(\omega) \underline{E}(\omega)
$$

Therefore

$$
\underline{\tilde{\varepsilon}_{r}}(\omega)=1+\chi^{\prime}(\omega)-i\left[\chi^{\prime \prime}(\omega)+\frac{\sigma_{0}}{\varepsilon_{0} \omega}\right]
$$

The dielectric dissipation factor is then defined as:

$$
\tan \delta(\omega)=\frac{\varepsilon_{r}^{\prime \prime}(\omega)+\frac{\sigma_{0}}{\varepsilon_{0} \omega}}{\varepsilon_{r}^{\prime}(\omega)}
$$

The real part of (5) represents the capacitance of a test object, whereas the imaginary part represents the losses. Both quantities depend on frequency. It should be noted that all dielectric quantities are more or less dependent on temperature and dissipation factor $\tan \delta$ is strongly dependent on temperature. Increased interfacial polarization also produces the increase in dissipation factor, mainly in the low and very low frequency range. The value of dissipation factor is related to the dielectric loss and its value can be regarded as a measure of the quality of the insulation system. Measurements in the frequency domain need voltage sources of variable frequencies and, for applications related to high-voltage power equipment, output voltages up to at least some hundreds of volts. Such measurements become quite lengthy if very low frequencies are considered [19], [20], [21].

\section{EXPERIMENT SETUP}

The experimental measurements were divided into two experiments and they were performed on 4 cable samples by the DRS method in frequency domain. Aim of measuring has been comparison of measured frequency dependencies of capacitance and dissipation factor. The measurement system was composed of LCR meter and PC with Agilent VEE software.

The experiment was studied the effect of long-term thermal ageing on dielectric parameters of XLPE insulation. The measurements of capacity and dissipation factor were performed on one power cable sample by precision LCR meter Agilent E4980A. The cable sample was a power cable of operationally unknown technical condition with an aluminium core and XLPE insulation. The cable length was approximately $25 \mathrm{~cm}$ and protective cable jacket and semiconducting layer have been removed ( $2 \mathrm{~cm}$ at both ends) and shielding taken out. At the beginning of the ageing process was measured dielectric parameters. Subsequently, it was kept accelerated ageing in an oven at the temperature of $90^{\circ} \mathrm{C}$ in the absence of any external electric field. The measurement was repeated, and the ageing time was squared. The frequency range of measurements was $100 \mathrm{~Hz}$ to $2 \mathrm{MHz}$. The increase of frequency was decimal.

\section{EXPERIMENT RESULT}

In Figure 1 and Figure 2 are shown comparison of frequency dependencies of capacitance and dissipation factor before and after thermal ageing process, respectively. Figure 1 shows a decrease of the values of capacitance after ageing process.

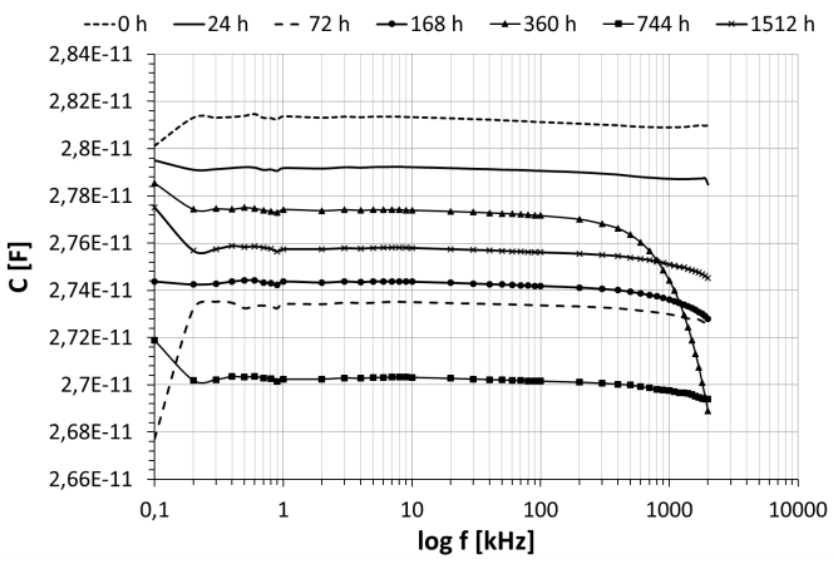

Fig. 1 Capacitance dependence on frequency for different thermal ageing times

The change of capacitance is very small, order of $10^{-}$ ${ }^{11} \mathrm{~F}$ and the trend of curves is about the same except for the curve measured after $360 \mathrm{~h}$ thermal aging. 


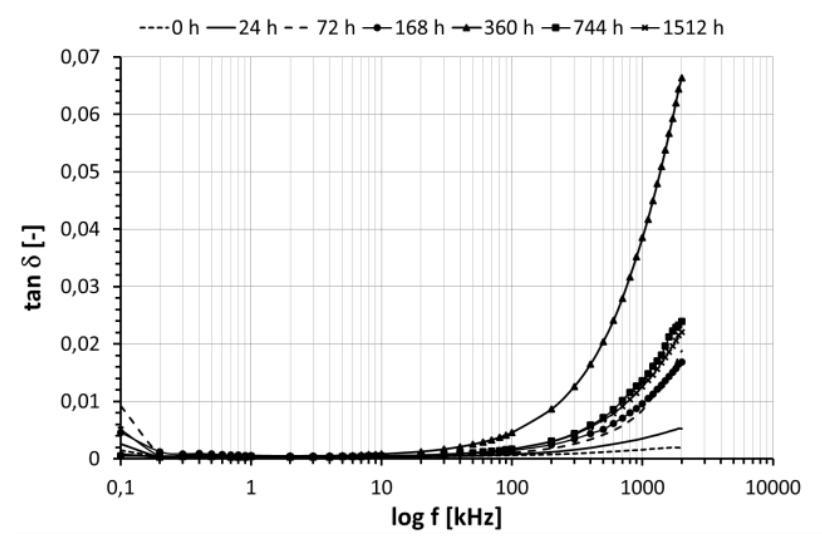

Fig. 2 Dissipation factor dependence on frequency for different thermal ageing times

This anomaly in the measurement was probably caused by final stabilization of added inhibitors in XLPE material during manufacturing.

The change of dissipation factor showed in Figure 2 is significant at high frequency from $10 \mathrm{kHz}$ where there was a significant and steeper increase in measured values. From frequency $100 \mathrm{~Hz}$ to $200 \mathrm{~Hz}$ there was a decrease in the measured values. For the curve measured after $360 \mathrm{~h}$ of aging is likely to once again show an anomaly in the measurement. The accelerated thermal aging process caused a change of frequency dependence of dissipation factor. It can be stated that the values of dissipation factor are greater and increase with aging time.

\section{DISCUSSION}

Using DRS in frequency domain can be evaluated the effect of temperature and thermal aging on dielectric parameters and change of properties of investigated insulation material after aging and degradation processes.

The showed characteristics shows effect of temperature on the XLPE insulation and the resulting changes of dielectric parameters of insulation. Such changes can be related to structural changes in the polyethylene $(\mathrm{PE})$ morphology. Intrinsic loss of non-degraded PE contains only electron polarization and conduction loss because it is the non-polar dielectric with no polar groups. During continuous heating, the crystalline area becomes amorphous area. This makes the oxygen diffusion in amorphous area of XLPE easier. The PE chain breaks into small chain of molecular easily under the combined effect of thermal and oxygen. The chain split into many polar bonds, which give rise to the increase of relaxation loss. The dielectric loss consists of conduction loss and relaxation loss. The relaxation loss can be neglected in high frequency region. The longer ageing time results in an increase of dielectric losses and $\tan \delta$. This can be explained as a consequence of the polarization and conduction processes.

\section{CONCLUSIONS}

Aim of this paper was to observe a change of dielectric parameters of XLPE cable due to thermal ageing. The quality and parameters of XLPE insulation are dependent on a number of factors that affect the insulation during operation. It is well known that temperature, moisture and degradation processes occurring in insulation influences on the parameters and quality of insulation. The comparison and evaluation of measured frequency dependencies of capacitance and dissipation factor show a change of dielectric properties of XLPE insulation. Such changes of parameters are due to thermal ageing, which will cause of changes in material properties as conductivity, permittivity, insulation resistivity and structural changes in the polyethylene morphology. The XLPE thermal-oxygen ageing leads to the impurities increased and non-polar chain break into pieces of small polar molecular chain which change the value of capacitance and dissipation factor. It is possible to confirm that degradation led to changes in the polarization processes occurring in insulation.

It is not possible exclude the surrounding of a disturbance during the measurement, which could affect the measured results but further research is needed. It is important to continue to investigate the processes of ageing and their impact on the insulation systems. It is also important to choose the suitable diagnostic methods and measuring equipment.

\section{ACKNOWLEDGMENTS}

"We support research activities in Slovakia "This project is being co-financed by the European Union". Paper is the result of the Project implementation: University Science Park TECHNICOM for Innovation Applications Supported by Knowledge Technology, ITMS: 26220220182, supported by the Research \& Development Operational Programme funded by the ERDF". Work was supported by VEGA 1/ 0311/15

\section{REFERENCES}

[1] PETZOLD, F. - GULSKI, E. - SEITZ, P. P. QUAK, B. - SCHLAPP, H.: Advanced solution for on-site diagnosis of distribution power cables, Electricity Distribution - Part 1, 2009, CIRED 2009, 20th International Conference and Exhibition; 2009; p.1-4.

[2] SHUVALOV, M. - MAVRIN, M. - OVSIENKO, V. - ROMASHKIN, A.: Analysis of Water Trees in Power Cable Polymeric Insulation, Journal Applied Polymer Science. 2003; vol.88: p. 1543-1549.

[3] FOTHERGILL, J. C. - DODD, S. J. - DiSSADO, L. - LIU, T. - NILSSON, U. H.: The Measurement of Very Low Conductivity and Dielectric Loss in XLPE Cables, IEE Transaction on Dielectrics Electrical Insulation. 2011; vol. 15(no. 5): p. 15441553.

[4] RAWANGPAI, A. - MARAUNGSRI, B. CHOMNAWANG, N.: Artificial Accelerated Ageing Test of $22 \mathrm{kV}$ XLPE Cable for Distribution System Applications in Thailand, World Academy of Science, Engineering and Technology 65. 2010, p. 220-225.

[5] HAMPTON, N. - HARTLEIN, R. LENNARTSSON, H. - ORTON, H. - 
RAMACHANDRAN, R.: Long-life XLPE Insulated Power Cable, Jicable 2007.

[6] METWALLY. A.: The Evolution of Medium Voltage Power Cables, Potentials, IEEE. 2012; vol. 31(no.3): p. 20-25.

[7] WALD, D. - HAMPTON, N.: How much does studying Polyethylene tell us about XLPE?, Electrical Insulation (ISEI), Conference Record of the 2012 IEEE International Symposium; 2012; p.250-254.

[8] JIANYING, L. - XUETONG, Z. - GUILAI, Y. SHENGTAO, L. - JIANKANG, Z. - BENHONG, O.: The Effect of Accelerated Water Tree Ageing on the Properties of XLPE Cable Insulation, IEEE Transaction on Dielectrics and Electrical Insulation. 2011; vol. 18: p. 1562-1569.

[9] WEIWEI, L. - et al.: Frequency dependence of breakdown performance of XLPE with different artificial defects, Dielectrics and Electrical Insulation, IEEE Transactions. 2012; vol. 19(no. 4): p.1351-1359.

[10] ABDERRAZZAQ, M. H. - HUSSIN, M. S. ALHAYEK, K.: The effect of high frequency, high voltage supply on the growth of electrical trees on cross linked polyethylene insulation of power cables, Solid Dielectrics (ICSD), 2013 IEEE International Conference; 2013 June 30-July 4; p.812,815.

[11] HOFF, G. - KRANZ, G. H.: Correlation between Return Voltage and Relaxation Current Measurements on XLPE Medium Voltage Cables, in: 11th ISH 1999; London.

[12] HOFF, G. - KRANZ, G. H.: Interpretation of Dielectric Response Measurement Data from Service Aged XLPE-Cables, IEEE 7th International Conference on Solid Dielectrics; 2001 June 25-29; Eindhoven; p. 381-384.

[13] THOMAS, A. J. - SAHA, T. K.: Statistical Analysis of Diagnostic Indicators during an Accelerated Ageing Experiment, IEEE Transactions on Dielectrics and Electrical Insulation. 2012; vol. 19(no. 1): p. 274-282.

[14] NIKOLAJEVIC, V. S.: Accelerated aging of XLPE and EPR cable insulations in wet conditions, Electrical Insulation, 1998. Conference Record of the 1998 IEEE International Symposium, 1998; vol.1, p.93-96.

[15] Ageing of XLPE Compounds, Brochure, General Cable Australia Pty Ltd.

[16] FEI, L. - XINGYI, H. - JING, W. - PINGKAI, J.: Insulation ageing diagnosis of XLPE power cables under service conditions, Condition Monitoring and Diagnosis (CMD), 2012 International Conference; 2012; p.647-650.

[17] TALREJA, M. - et al.: The effect of thermal aging on the electrical breakdown strength of crosslinked polyethylene, Electrical Insulation Conference (EIC), 2014, pp.162,166, 8-11 June 2014.
[18] SHIMADA, A. - et al.: Degradation distribution in insulation materials of cables by accelerated thermal and radiation ageing, Dielectrics and Electrical Insulation, IEEE Transactions, vol.20, no.6, pp.2107,2116, December 2013.

[19] JI, Liu - YOU, Xu - XINLAO, Wei - XIUJING, Li: Research of Dielectric spectroscopy on insulation ageing assessment of XLPE cables, Electrical Insulation and Dielectric Phenomena (CEIDP), 2013 IEEE Conference, pp.140,143, 20-23 Oct. 2013.

[20] BUCHNER R.: Dielectric spectroscopy of solutions, Novel Approaches to the Structure and Dynamics of Liquids: Experiments, Theories and Simulations; 2004, p. 265-288.

[21] ZAENGL, W. S.: Dielectric Spectroscopy in Time Domain for HPV Power Equipment, Part I: Theoretical Consideration, IEE Transaction on Dielectrics Electrical Insulation. 2003; vol. 19(no. 5): p. 5-19.

[22] FOURMIGUE, J.M. - PARPAL, J.L. - SEGUIN, J.N.: Dielectric spectroscopy of XLPE cable insulation: comparison between time-domain and frequency-domain methods, Proceedings of the 4th International Conference on Conduction and Breakdown in Solid Dielectrics, pp.235-240.

Received July 7, 2015, accepted October 7, 2015

\section{BIOGRAPHIES}

Roman Cimbala was born in Košice (Slovakia). He graduated the Technical University of Košice, Faculty of Electrical Engineering and Informatics in Košice (Slovakia), in 1986. He received the $\mathrm{PhD}$ degree in electrical engineering from the Slovak University of Technology in Bratislava (Slovakia), in 1994. He is Professor at the Technical University of Košice (Slovakia). His research interests concern: dielectric spectroscopy, diagnostics of HV systems.

Martin German-Sobek was born in Košice (Slovakia). He graduated the Technical University of Košice, Faculty of Electrical Engineering and Informatics in Košice (Slovakia), in 2011. He received the $\mathrm{PhD}$ degree in electrical power engineering from the Technical University of Košice, Faculty of Electrical Engineering and Informatics in Košice (Slovakia), in 2015 His research interests concern: diagnostic of high-voltage solid insulation system, high-voltage equipment, power cables.

Samuel Bucko Samuel Bucko was born in Prešov (Slovakia). He graduated the Technical University of Kosice, Faculty of Electrical Engineering and Informatics in Kosice (Slovakia), in 2013. He actually studies the PhD degree in electrical power engineering and informatics in Kosice (Slovakia). His research interests concern: Diagnostic of $\mathrm{HV}$ liquid insulation system and $\mathrm{HV}$ equipment. 